\title{
NOVA FORMA DE ACESSO AO ENSINO SUPERIOR PÚBLICO: UM ESTADO DO CONHECIMENTO SOBRE O SISTEMA DE SELEÇÃO UNIFICADA - SiSU
}

\begin{tabular}{c}
\hline NEW WAY OF ACCESS TO PUBLIC HIGHER EDUCATION: \\
A STATE OF KNOWLEDGE ON THE UNIFIED SELECTION SYSTEM - SiSU \\
NUEVA FORMA DE ACCESO A LA ENSEÑANZA SUPERIOR PÚBLICA: \\
UN ESTADO DEL CONOCIMIENTO SOBRE EL SISTEMA DE \\
SELECCIÓN UNIFICADA - SiSU
\end{tabular}

\section{Thainara Cristina de Castro Ariovaldo ${ }^{i}$ Cláudio Marques Martins Nogueira}

\begin{abstract}
RESUMO: Este trabalho apresenta um estado do conhecimento sobre o Sistema de Seleção Unificada - SiSU. Tomou-se por objeto o conjunto de trabalhos cadastrados no banco de teses e dissertações mantido pela CAPES que tratam do assunto. A seleção dos trabalhos $(n=16)$ foi feita com base nas fichas cadastrais e resumos e as análises foram feitas com enfoque nos resumos, introduções e conclusões apresentados pelos autores. Com base nestes dados, foi possível traçar um panorama da produção científica brasileira contemporânea sobre o SiSU, no âmbito dos programas de pós-graduação, identificando suas principais tendências, bem como resultados convergentes e divergentes.
\end{abstract}

PALAVRAS-ChAVE: Acesso ao Ensino Superior. Sistema de Seleção Unificada (SiSU). Estado do Conhecimento.

ABSTRACT : This paper presents a state of knowledge about the Unified Selection System - SiSU. The object of the study was the set of papers registered in the theses and dissertations maintained by CAPES that deal with the subject. The selection of papers $(n=16)$ was done based on the cadastral records and abstracts and the analysis were made with a focus on the abstracts, introductions and conclusions presented by the authors. Based on these data, it was possible to draw a panorama of contemporary Brazilian scientific production on SiSU, within the scope of postgraduate programs, identifying its main trends, such as convergent and divergent results.

KEYWORDS: Access to Higher Education. Unified Selection System (SiSU). Knowledge State.

RESUMEN : Este trabajo presenta un estado del conocimiento sobre el Sistema de Selección Unificada - SiSU. Se tomó por objeto del estudio el conjunto de trabajos registrados en el banco de tesis y disertaciones mantenido por la CAPES que tratan del asunto. La selección de los trabajos $(n=16)$ fue hecha con base en las fichas catastrales y resúmenes y los análisis se hicieron con mayor atención en los resúmenes, introducciones y conclusiones presentadas por los autores. Con base en estos datos, fue posible trazar un panorama de la producción científica brasileña contemporánea acerca del SiSU, en el ámbito de los programas de postgrado, logrando identificar sus principales tendencias, así como resultados que se convergen y divergen.

PAlabRAS Clave: Acceso a la enseñanza superior. Sistema de Selección Unificada (SiSU). Estado del Conocimiento.

\footnotetext{
${ }^{1}$ Submissão em: 10/10/2017 - Aceito em:23/10/2017 - Publicado em: 31/10/2017.

\begin{tabular}{l|l|l|l|l|l} 
(C) Rev. Inter. Educ. Sup. & Campinas, SP & v.4 & n.1 & p.152-174 & jan./abr. 2018
\end{tabular}
}




\section{INTRODUÇÃo}

Em 2010 o Ministério da Educação (MEC) criou um novo mecanismo de seleção para admissão ao ensino superior público: o Sistema de Seleção Unificada (SiSU). Esse sistema foi proposto tendo como objetivos a redução dos gastos com a realização de exames de seleção descentralizados; a diminuição das ineficiências observadas na ocupação das vagas (acúmulo de vagas ociosas ${ }^{2}$ ); a democratização do acesso à educação superior e a ampliação da mobilidade geográfica estudantil. Até então, o acesso ao ensino superior público se dava por meio do vestibular tradicional, processo seletivo descentralizado, formulado e aplicado pelas instituições isoladamente ou, no máximo, por um conjunto de instituições parceiras. Desde sua implantação o SiSU apresentou uma crescente adesão por parte das instituições de educação superior, as quais passaram a utilizá-lo total ou parcialmente no lugar do tradicional vestibular.

O ponto inicial para as mudanças no acesso às instituições públicas no Brasil ocorreu no começo de 2009. Na ocasião, o MEC apresentou, por meio do documento "Proposta à Associação Nacional dos Dirigentes das Instituições Federais de Ensino Superior" (ANDIFES), a defesa da criação de um novo sistema de ingresso centralizado que utilizaria as notas dos alunos no Exame Nacional do Ensino Médio (ENEM). Com base nessa proposta inicial, foi apresentado também pelo MEC e no mesmo ano o "Termo de Referência - Novo ENEM e SiSU", no qual é explicitado o novo papel a ser cumprido pelo ENEM e, além disso, são apresentadas as regras gerais de funcionamento do novo processo seletivo.

No início do ano seguinte, 26 de janeiro de 2010, foi instituído e regulamentado, por meio da Portaria Normativa ${ }^{\circ}$ 02, o Sistema de Seleção Unificada (SiSU), definido como um sistema informatizado para seleção de candidatos a vagas em cursos de graduação disponibilizadas pelas instituições públicas de educação superior dele participantes. Ressalta-se que a adesão a esta forma de ingresso seria adotada pelas instituições de forma voluntária e que estas poderiam utilizá-las como forma de ingresso única ou associada a outras formas de seleção. Luz (2013, p. 102), ressalta que

tal Sistema foi pensado com a intencionalidade de proporcionar a concorrência de vagas em qualquer IES que aderisse ao Sistema de Seleção, possibilitando ao estudante realizar a prova no seu próprio estado e cidade, sem a necessidade exigida pelo vestibular tradicional, no qual era necessário deslocamento até a cidade para realizar a prova, ou seja, cria oportunidades de concorrer a vagas, agora em nível nacional, o que de fato é a questão chave do SiSU, 'a seleção nacional'.

\footnotetext{
${ }^{2}$ São consideradas vagas ociosas as vagas não ocupadas nos cursos. A não ocupação pode ser em virtude de número de matriculados aquém do número de vagas ofertadas ou por evasão dos alunos no decorrer dos cursos.
} 
O funcionamento dessa seleção é descrito por Abreu e Carvalho (2014, p.9) como um "mecanismo de matching" (pareamento), em que há um ajustamento feito pelo candidato entre vagas e instituições do ensino superior de todo território nacional e suas possibilidades de êxito. Este procedimento também foi analisado pelos trabalhos de Nogueira et al (2017) e Almeida et al (2016). O "mecanismo de matching" induz a um jogo que, no caso do SiSU, percorre as seguintes etapas:

1) Jogo de Sinalização: Trata-se de um intervalo de três ${ }^{3}$ dias em que os alunos podem realizar suas inscrições (BRASIL, 2017). Neste período, a qualquer momento, o aluno pode acessar a plataforma do sistema e escolher, em ordem de preferência, até duas ${ }^{4}$ opções de curso ofertados pelas instituições que aderiram ao SiSU. A partir daí, o sistema faz simulações que permitem ao estudante perceber qual sua colocação no jogo, apontando ao aluno a "classificação parcial" (ABREU; CARVALHO, 2014, p.10). Na plataforma também é possível que o aluno tenha acesso às notas de corte atualizadas de qualquer curso participante do processo de seleção. Desse modo, as escolhas podem ser alteradas no decorrer do processo com base nestas informações sobre a posição diária do candidato em relação aos demais concorrentes (ALMEIDA et al, 2016).

2) Procedimento de matching: Trata-se do último dia de inscrição em que o aluno, após todas as simulações, sinaliza em quais cursos ele realmente irá se candidatar em primeira e segunda opção. Com base nessas indicações, o sistema calcula a classificação dos candidatos e realiza ofertas de vagas aos mais bem posicionados. "Cada estudante que recebe oferta decide por aceitar, assegurando sua vaga, ou rejeitar essa oferta, disponibilizando a vaga para ser reofertada em etapa posterior" (ABREU; CARVALHO, 2014 , p.11). Aqueles que receberam oferta de uma vaga para o curso que haviam indicado como primeira opção têm que escolher entre aceitar essa oferta ou sair do jogo sem nenhuma outra vaga. Aqueles que são aprovados para um curso que indicaram como segunda opção podem aceitar ou não essa oferta e, independente disso, manifestar interesse de continuar esperando uma nova chamada para o curso que indicaram como primeira opção. Aos candidatos que não receberam nenhuma oferta só restaria aguardar por novas oportunidades na fase seguinte do jogo.

3) Ajuste de matching: Trata-se da etapa em que as vagas rejeitadas são reofertadas através de lista de espera. "As vagas não ocupadas pelos candidatos aprovados e convocados pelo próprio sistema são redirecionadas para aqueles que manifestaram interesse em participar das listas de espera”. (NOGUEIRA et al, 2017, p.6). É por meio destas listas

\footnotetext{
${ }^{3}$ Foi a partir do processo seletivo de 2016/1 que se restringiram os dias do processo a três. Antes disso, a plataforma online do SiSU ficava disponível para alterações por cinco dias.

${ }^{4}$ A Portaria Normativa $\mathrm{n}^{\circ} 2$ dispunha que seria possível que os candidatos escolhessem até cinco opções de cursos, mas a partir de 2012 o candidato passou a escolher apenas duas opções.

\begin{tabular}{l|l|l|l|l|l} 
(C) Rev. Inter. Educ. Sup. & Campinas, SP & v.4 & n.1 & p.152-174 & jan./abr. 2018 \\
\hline
\end{tabular}
}


que as instituições realizam diversas chamadas até que se preencha a totalidade das vagas disponibilizadas.

Nogueira et al (2017), destacam três supostas vantagens do SiSU em relação ao vestibular tradicional: 1) há perspectiva de ganhos operacionais e de custo para as instituições, através de um processo seletivo mais barato e eficiente e promoção também de maior eficiência na ocupação das vagas, disponibilizando-as para estudantes de todo país; 2) "o SiSU teria a vantagem de propiciar maior mobilidade geográfica aos estudantes, ampliando trocas acadêmicas e culturais e a própria integração do país" (p.2); 3 ) Com sua articulação com a Lei de Cotas, "este mecanismo traria maior inclusão de alunos pertencentes a grupos subrepresentados no ensino superior brasileiro" (p. 3). Tendo como referência os dados da UFMG, os autores destacaram que a realização dessas promessas não parece integral e que novos estudos a respeito dos efeitos do SiSU ainda precisariam ser realizados.

Dada a importância da mudança inaugurada pelo SiSU no acesso à educação superior pública e as incertezas ainda existentes sobre suas reais consequências, faz-se necessário acompanhar o que tem sido pesquisado a respeito, até mesmo para subsidiar e provocar novas análises. Por isso, o objetivo deste trabalho é tomar o SiSU como objeto de um estado do conhecimento por meio de consulta às dissertações ${ }^{5}$ defendidas nos Programas de Pós-Graduação brasileiros cadastrados no banco de teses e dissertações mantido pela Coordenação de Aperfeiçoamento de Pessoal de Nível Superior (CAPES). Os trabalhos selecionados são aqueles que têm como objetivo compreender o SiSU, sua implementação e seus efeitos sobre o acesso ao ensino superior público brasileiro.

Luz (2013) apresentou um mapeamento sobre o tema em sua dissertação, realizada no segundo semestre de 2011, semelhante ao mapeamento que propomos. O objetivo da autora foi levantar no Banco de Teses e Dissertações CAPES, com base nas palavras-chave "acesso à educação superior", "mecanismo de seleção, processo seletivo", "forma de ingresso, vestibular", "Novo Enem e SiSU", trabalhos sobre acesso ao Ensino Superior brasileiro. Foram encontrados 13 trabalhos publicados de 1994 a 2010 e nenhuma produção a respeito do SiSU. De modo semelhante, Oliveira (2014) apresenta em seu trabalho 15 dissertações e duas teses encontradas no mesmo banco de teses no período de 2010 a 2012, com base em palavras-chave análogas às mencionadas por Luz (2013) e também não obteve nenhum trabalho a respeito do SiSU.

Dando continuidade a esses esforços iniciais de mapeamento das pesquisas sobre o tema, nosso trabalho se concentra no período que vai de 2013 a 2017, focalizando os trabalhos publicados no Banco de Teses e Dissertações da Capes que efetivamente buscam entender,

\footnotetext{
${ }^{5}$ Devido ao curto tempo de implementação do SiSU, não foi encontrada nenhuma tese em meio aos trabalho cadastrados no banco da CAPES.

\begin{tabular}{l|l|l|} 
(C) Rev. Inter. Educ. Sup. & Campinas, SP & v.4
\end{tabular}

n. 1

p.152-174 jan./abr. 2018
} 
explicar e explicitar como o SiSU tem se consolidado, seja de forma mais ampla ou em contextos institucionais particulares.

\section{METODOLOGIA}

Este trabalho adota uma investigação de caráter bibliográfico e descritivo, apresentando as características de um "estado do conhecimento", segundo a classificação de Romanowski e Ens (2006). Para tais autoras, a denominação "estado da arte" é mais apropriada quando o estudo abrange a produção de conhecimento em uma determinada área científica, dando enfoque aos vários tipos de publicações disponíveis, como teses e dissertações, trabalhos apresentados em congressos, livros, artigos em periódicos científicos, etc. Já os estudos, como que abordam um único tipo de publicação sobre um tema seriam nomeados mais adequadamente como "estado do conhecimento".

Ressalta-se que antecedendo a análise dos trabalhos disponíveis no Banco de Teses e Dissertações, o primeiro passo da pesquisa foi um levantamento bibliográfico geral, via internet, com o objetivo de verificar todos os meios de produção científica (periódicos de artigos científicos, trabalhos em congressos, teses e dissertações). Esta primeira busca revelou o que já era esperado: dado o pouco tempo de implementação do SiSU, um incipiente, mas em crescimento, número de trabalhos que objetivam entender seu processo de implementação e consequências. Além disso, observou-se que muitos dos artigos encontrados têm como base as dissertações disponibilizadas no banco de teses. Por isso, e também para tornar o foco do trabalho melhor delimitado, tomou-se a decisão de investigar somente os trabalhos do banco de teses e dissertações da CAPES.

As palavras-chave utilizadas nas buscas deste mapeamento foram, "SiSU" e "Sistema de Seleção Unificada". A partir da leitura dos títulos e resumos dos trabalhos encontrados, selecionamos aqueles que contemplassem em seus objetivos a proposta dessa investigação. Chegamos assim a dezesseis dissertações ${ }^{6}$ e nenhuma tese ${ }^{7}$.

\footnotetext{
${ }^{6}$ Por meio das palavras-chave SiSU e Sistema de Seleção Unificada foram encontrados três trabalhos que não se enquadram na investigação aqui proposta de analisar trabalhos que explorem as consequências da implementação do SiSU para a educação superior: Santin (2014) objetivou realizar uma análise sobre o desenvolvimento econômico local e a relação com as políticas públicas REUNI e SiSU implementadas na UFPel; Costa (2013) visou apontar e discutir a importância da Estatística para o ensino fundamental e médio por meio do tema integrador Sistema de Seleção Unificada - SiSU; e o trabalho de Gaia (2017) teve como finalidade a proposição de um documento/manual, o qual seria utilizado de comunicação institucional na Universidade Federal do Triângulo Mineiro e como norteador quanto ao ingresso inicial nos cursos de graduação, elencando diferenças entre o SiSU e o vestibular tradicional.

${ }^{7}$ A busca foi realizada em meados de agosto de 2017, trabalhos publicados no banco de teses a partir deste mês não encontram-se analisados aqui.
}

\begin{tabular}{|l|l|l|l|l|l|} 
(C) Rev. Inter. Educ. Sup. & Campinas, SP & v.4 & n.1 & p.152-174 & jan./abr. 2018 \\
\hline
\end{tabular}


Os trabalhos selecionados foram realizados em cinco programas de Mestrado Profissional e onze programas de Mestrado Acadêmico de doze instituições diferentes, todas públicas. Quanto à origem institucional, verifica-se a seguinte distribuição:

Quadro 1. Distribuição das dissertações segundo instituições

\begin{tabular}{|c|c|}
\hline Instituição & Número de trabalhos \\
\hline Universidade Federal do Ceará (UFC) & 2 \\
\hline Universidade Federal do Mato Grosso (UFMT) & 2 \\
\hline Universidade Federal da Grande Dourados (UFGD) & 2 \\
\hline Universidade Federal de Viçosa (UFV) & 2 \\
\hline Universidade Federal de Lavras (UFLA) & 1 \\
\hline Universidade Estadual de Maringá (UEM) & 1 \\
\hline Universidade Federal do Piauí (UFPI) & 1 \\
\hline Universidade Federal de Santa Catarina (UFSC) & 1 \\
\hline Universidade Estadual de São Paulo (UNESP) & 1 \\
\hline Universidade Federal de Brasília (UFB) & 1 \\
\hline Universidade Federal da Bahia (UFBA) & 1 \\
\hline Universidade de São Paulo (USP) & . \\
\hline
\end{tabular}

Fonte: Elaboração própria com base nos dados do Banco de Teses e Dissertações da CAPES.

Do ponto de vista de sua vinculação às áreas do conhecimento, os trabalhos se distribuem em cinco grupos, sendo que a maior concentração ocorre na área da Educação, como apontado no gráfico a seguir:

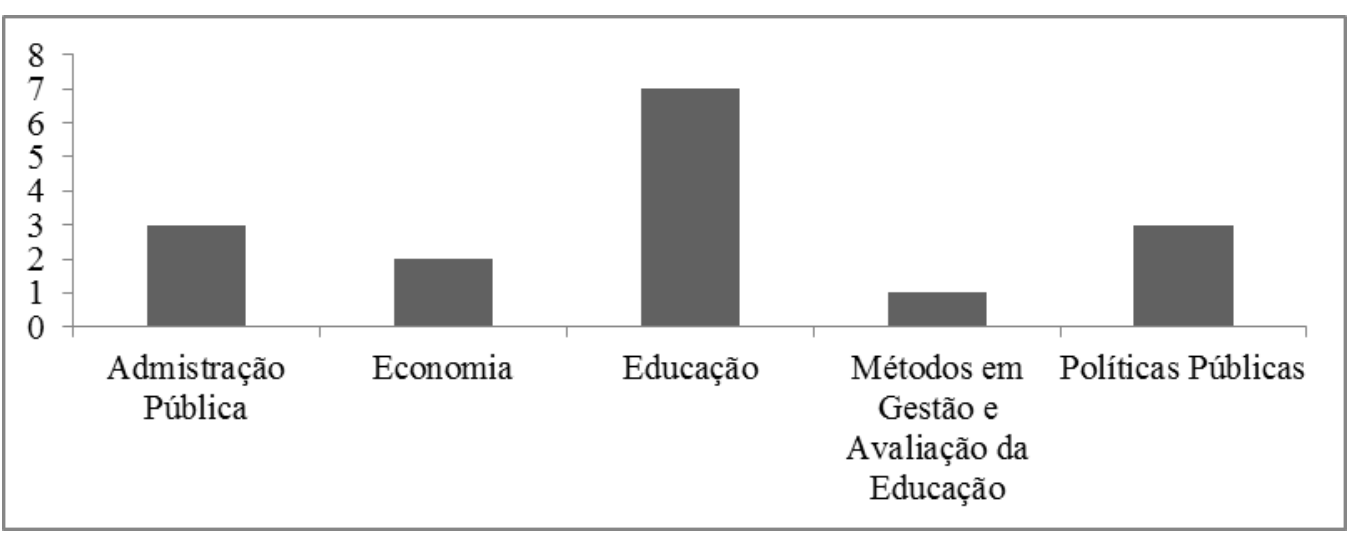

Gráfico 1. Distribuição das dissertações encontradas no Banco de Teses e Dissertações da CAPES segundo área do conhecimento

Fonte: Feito pelos autores com base no Banco de Teses e Dissertações da CAPES

Em termos da distribuição geográfica dos trabalhos, nota-se que há uma participação semelhante das regiões Nordeste, Centro-oeste e Sudeste. A região sul teve um número menor de trabalhos identificados e a região norte nenhum, conforme Gráfico 2. 


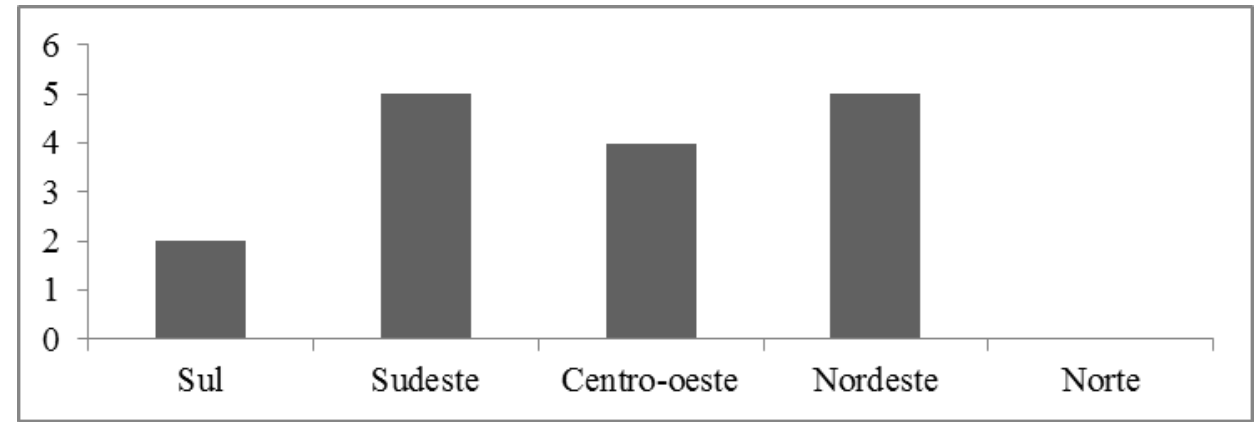

Gráfico 2. Distribuição regional das dissertações encontradas no

Banco de Teses e Dissertações da CAPES.

Fonte: Feito pelos autores com base no Banco de Teses e Dissertações da CAPES

A partir da seleção das dissertações, foi feito um trabalho de análise em três partes. Inicialmente investigamos como é feita a delimitação do objeto em cada investigação. Foi possível classificar os trabalhos em três grupos, em função do modo específico como discutem o SiSU. Em seguida, analisamos as opções metodológicas adotadas pelas dissertações, considerando sobretudo como elas se definem em termos de sua proximidade com as abordagens quantitativa e qualitativa. Por último, analisamos os principais resultados das dissertações, buscando ressaltar suas contribuições para algumas discussões básicas relativas ao SiSU já mencionadas anteriormente: efeitos sobre o processo de escolha dos cursos superiores; maior eficiência na ocupação das vagas e mobilidade geográfica estudantil; e democratização do acesso. Para isso, além de uma leitura geral dos trabalhos, foi feita uma análise pormenorizada e de caráter comparativo dos resumos, introduções e capítulos conclusivos destas 16 produções científicas.

\section{RESULTADOS}

\section{O SiSU SOB DIFERENTES ÂNGULOS: 0 MODO COMO 0 OBJETO É DELIMITADO NAS DISSERTAÇÕES}

As dissertações aqui analisadas justificam a escolha do SiSU como objeto de estudo pelas diferentes inovações que ele introduz no processo de seleção para o ensino superior público e pelas promessas que ele traz de maior democratização do acesso, eficiência na ocupação das vagas e mobilidade geográfica.

$\mathrm{Na}$ maior parte dos casos, as dissertações não se dedicam a analisar um aspecto ou uma consequência muito específica do SiSU, mas diferentes repercussões da adoção desse sistema sobre o acesso às instituições de ensino superior. Essa tendência a adotarem um recorte mais amplo do objeto é compreensível considerando-se o modo abrangente e multidimensional 
como o SiSU afeta o acesso ao ensino superior. É de fato difícil isolar uma única dimensão do objeto.

No que pese a tendência das dissertações à abordagem do Sistema de forma mais geral, é possível classificá-las por sua ênfase em diferentes dimensões ou efeitos do novo mecanismo. Assim, categorizamos os trabalhos em três grupos em função de seus objetivos. As categorias são: trabalhos que se dedicam a analisar o processo de decisão/escolha dos cursos (PD), trabalhos que analisam como tem se dado a ocupação de vagas e a mobilidade geográfica $(\mathrm{OV})$ e trabalhos que tem enfoque na democratização ${ }^{8}$ (DEM).

Um primeiro grupo de trabalhos (ver Quadro 2) se dedica mais diretamente às mudanças no processo de tomada de decisão por parte dos candidatos durante o processo de seleção, ressaltando seu impacto sobre a escolha dos cursos superiores.

Quadro 2. Trabalhos que investigaram o processo de decisão dos alunos no processo seletivo

\begin{tabular}{|c|c|c|}
\hline Título & Autoria & Objetivo \\
\hline $\begin{array}{l}\text { Mecanismos de Seleção de } \\
\text { Gale-Shapley Dinâmicos em } \\
\text { Universidades Brasileiras: } \\
\text { SISU, SISU } \alpha \text {, SISU } \beta\end{array}$ & $\begin{array}{l}\text { Abreu } \\
(2013)\end{array}$ & $\begin{array}{l}\text { Buscar, sob a luz da teoria dos jogos, entender os incentivos } \\
\text { dados pelo Sistema de Seleção Unificado (SISU) através do } \\
\text { desenvolvimento e análise de modelos estilizados, i.e., dos } \\
\text { mecanismos SISU } \alpha \text { e SISU } \beta \text {. }\end{array}$ \\
\hline $\begin{array}{l}\text { A Escolha do Curso Superior no } \\
\text { Sistema de Seleção Unificada - } \\
\text { SiSU: o caso do curso de } \\
\text { enfermagem da Universidade } \\
\text { Federal de Mato Grosso, } \\
\text { Campus Universitário de Sinop }\end{array}$ & $\begin{array}{l}\text { Flores } \\
(2013)\end{array}$ & $\begin{array}{l}\text { Analisar o processo de ingresso acadêmico no curso de } \\
\text { enfermagem na Universidade Federal de Mato Grosso, Campus } \\
\text { Universitário de Sinop, tomando como base o período acadêmico } \\
\text { de 2012/1, ressaltando o processo de decisão dos estudantes pelo } \\
\text { curso, em face da nova forma de seleção proposto pelo Ministério } \\
\text { da Educação constituído do Exame Nacional do Ensino Médio - } \\
\text { ENEM/Sistema de Seleção Unificada - SiSU. }\end{array}$ \\
\hline $\begin{array}{l}\text { Análise das Escolhas do Curso } \\
\text { Superior pelos Certificandos } \\
\text { Participantes do ENEM, que } \\
\text { Ingressaram em uma IES, por } \\
\text { meio do SiSU, no Período 2012- } \\
2014\end{array}$ & $\begin{array}{l}\text { Paula } \\
\text { (2015) }\end{array}$ & $\begin{array}{l}\text { Apresentar uma análise do perfil dos certificandos do Ensino } \\
\text { Médio por meio do ENEM, que conseguiram ingressar em uma } \\
\text { das Instituições de Ensino Superior através do SISU, no período } \\
\text { entre } 2012 \text { a } 2014 \text {. }\end{array}$ \\
\hline
\end{tabular}

Fonte: Elaboração própria com base nos dados do Banco de Teses e Dissertações da CAPES.

\footnotetext{
${ }^{8}$ Ou seja, trabalhos que buscam perceber em que medida o SiSU tem contribuído para que públicos que tradicionalmente não acessavam instituições ou cursos específicos passem a fazê-lo. O conceito de democratização tem sido utilizado para se referir não apenas à massificação ou expansão do acesso, mas sobretudo à equalização das oportunidades entre indivíduos ou grupos sociais (MERLE, 2009;DUBET, 2015).
}

\begin{tabular}{|l|c|c|c|c|c|}
\hline C) Rev. Inter. Educ. Sup. & Campinas, SP & v.4 & n.1 & p.152-174 & jan./abr. 2018 \\
\hline
\end{tabular}


A dissertação de Abreu (2013) parte da constatação da ausência de trabalhos cuja temática seja o SiSU e suas especificidades na literatura econômica e propõe testar a eficiência interpretativa do mecanismo de matching para entender a lógica do "jogo" induzido pelo SiSU. Já as dissertações de Flores (2013) e Paula (2015) analisam especificamente a escolha dos cursos dentro das novas regras implementadas. Flores (2013) define o tema de pesquisa após constatar empiricamente, por meio do exercício docente no curso de Enfermagem da UFMT, uma mudança acentuada no perfil dos alunos do curso, que caberia ser investigada. Já Paula (2015), se interessa pelo modo como os estudantes que obtiveram o certificado de Ensino Médio por meio do ENEM $^{9}$ e ingressaram no Ensino Superior via SiSU se distribuem nos cursos.

As preocupações desse primeiro grupo de dissertações se justificam pelo fato do SiSU afetar diretamente o modo como os candidatos escolhem seus cursos. Como já observamos anteriormente, no SiSU, o candidato realiza sua escolha de curso já tendo acesso à sua própria nota, obtida no ENEM do ano anterior além das notas de corte estimadas para cada curso, atualizadas diariamente ${ }^{10}$. Essas informações permitem estabelecer com maior precisão um ajustamento entre suas escolhas e as opções em que pode realmente ser aprovado. Já no vestibular tradicional, o concorrente tem acesso somente às notas de corte de cada curso nos anos anteriores, assim, a possibilidade de ajustamento das preferências às probabilidades reais de aprovação é mais difícil e se dá com menos exatidão.

Cabe ressaltar que o SiSU prevê um mecanismo dinâmico de simulações, já descrito na introdução deste trabalho, que permite aos candidatos modificarem suas escolhas na plataforma online durante os dias de inscrição, em função das probabilidades de aprovação em cada curso. Como já discutimos, essas simulações induzem os candidatos a adequarem suas preferências à realidade, escolhendo o que parece efetivamente possível e não o mais desejado. Nada mais natural, portanto, que uma das preocupações presentes nas dissertações seja justamente com as repercussões do SiSU sobre a escolha dos cursos superiores.

Um segundo conjunto de dissertações focaliza os efeitos do SiSU sobre o processo de ocupação das vagas, incluindo os fenômenos da mobilidade geográfica, da permanência e da evasão $^{11}$ nos cursos e instituições. A definição desse enfoque por um conjunto expressivo de

\footnotetext{
${ }^{9}$ A última edição em que o ENEM serviu como instrumento de certificação do Ensino Médio foi em 2016. A partir dela, as certificações foram concentradas no Exame Nacional para Certificação de Competências de Jovens e Adultos (Encceja).

${ }^{10}$ Durante o período de inscrição, uma vez por dia, o SiSU calcula a nota de corte (menor nota para ficar entre os potencialmente selecionados) para cada curso com base no número de vagas disponíveis e no total dos candidatos que indicaram aquele curso até o momento, por modalidade de concorrência.

${ }^{11}$ Segundo definição do MEC, o fenômeno da evasão é a saída definitiva do curso de origem sem conclusão ou a diferença entre ingressantes e concluintes após uma geração completa - definida pelo prazo máximo do curso (FRITSCH et al, 2015)
}

(C) Rev. Inter. Educ. Sup. Campinas, SP v.4

n.1 p. $152-174$ jan./abr. 2018 
dissertações é bastante compreensível, pois se mostra necessário avaliar em que medida as expectativas positivas em relação aos impactos do SiSU sobre a ocupação das vagas se cumpriram e se eventualmente surgiram consequências perversas, como a elevação das taxas de evasão. Essas são as preocupações das dissertações agrupadas a seguir.

Quadro 2. Trabalhos cujos objetivos centram-se na ocupação de vagas no ensino superior público

\begin{tabular}{|c|c|c|}
\hline Título & Autoria & Objetivo \\
\hline $\begin{array}{l}\text { Políticas Públicas de } \\
\text { democratização do ensino superior: } \\
\text { um estudo sobre a ocupação das } \\
\text { vagas nos cursos de graduação na } \\
\text { Universidade Tecnológica Federal } \\
\text { do Paraná - campus Francisco } \\
\text { Beltrão }\end{array}$ & Czerniaski (2014) & $\begin{array}{l}\text { Analisar a não ocupação das vagas nos cursos de } \\
\text { graduação da Universidade Tecnológica Federal do } \\
\text { Paraná - Câmpus Francisco Beltrão. }\end{array}$ \\
\hline $\begin{array}{l}\text { Acesso à Educação Superior pelo } \\
\text { Enem/SiSU: uma análise da } \\
\text { implementação nas universidades } \\
\text { sul-mato-grossenses }\end{array}$ & Oliveira (2014) & $\begin{array}{l}\text { Analisar o processo de implementação do } \\
\text { ENEM/SiSU como instrumento de acesso à } \\
\text { educação superior pública em Mato Grosso do Sul, } \\
\text { considerando o processo de ocupação das vagas } \\
\text { ofertadas e a democratização do acesso de } \\
\text { candidatos ao processo seletivo para a educação } \\
\text { superior. }\end{array}$ \\
\hline $\begin{array}{l}\text { Os efeitos do SiSU no acesso ao } \\
\text { ensino superior: os fatores } \\
\text { condicionantes da não ocupação } \\
\text { das vagas pelos convocados na } \\
\text { Universidade Federal do Piauí }\end{array}$ & Sousa (2015) & $\begin{array}{l}\text { Encontrar pistas sobre os fatores que levam à sobra } \\
\text { de vagas, ou seja, à não efetivação das matrículas } \\
\text { pelos convocados do SiSU na UFPI. }\end{array}$ \\
\hline $\begin{array}{l}\text { Acesso e Permanência de Alunos } \\
\text { de Engenharia da UTFPR - } \\
\text { Campus Medianeira }\end{array}$ & Gómez (2015) & $\begin{array}{l}\text { Avaliar o ingresso, a permanência e a decorrente } \\
\text { evasão, com enfoque específico sobre os cursos } \\
\text { superiores de Engenharia na UTFPR - Câmpus } \\
\text { Medianeira. }\end{array}$ \\
\hline $\begin{array}{l}\text { Políticas Públicas de Acesso ao } \\
\text { Ensino Superior: os Resultados do } \\
\text { SiSU na Universidade Federal De } \\
\text { Viçosa }\end{array}$ & Rodrigues (2016) & $\begin{array}{l}\text { Abordar os resultados do SISU, na Universidade } \\
\text { Federal de Viçosa (UFV)- Campus Sede, no que } \\
\text { tange ao acesso, permanência e desempenho dos } \\
\text { estudantes. }\end{array}$ \\
\hline $\begin{array}{l}\text { Percursos de Formação de } \\
\text { Estudantes de Licenciatura Noturna } \\
\text { na UFV: ENEM, SiSU e Evasão }\end{array}$ & Rigo (2016) & $\begin{array}{l}\text { Compreender e problematizar as trajetórias } \\
\text { acadêmicas dos estudantes que ingressaram nas } \\
\text { licenciaturas noturnas de ciências biológicas, } \\
\text { física, matemática e química, criadas a partir do } \\
\text { Programa de Apoio a Planos de Reestruturação e } \\
\text { Expansão das Universidades Federais (REUNI), } \\
\text { por meio do Sistema de Seleção Unificada (SiSU) } \\
\text { em } 2012 \text { na Universidade Federal de Viçosa }\end{array}$ \\
\hline
\end{tabular}

\begin{tabular}{l|l|l|l|l|l} 
(C) Rev. Inter. Educ. Sup. & Campinas, SP & v.4 & n.1 & p.152-174 & jan./abr. 2018 \\
\hline
\end{tabular}




\begin{tabular}{|l|l|l|}
\hline & & (UFV). \\
\hline $\begin{array}{l}\text { O Novo ENEM e a plataforma } \\
\text { SiSU: efeitos sobre a migração e a } \\
\text { evasão estudantil }\end{array}$ & Li (2016) & $\begin{array}{l}\text { Investigar os impactos dessa política na migração } \\
\text { inter e intraestadual e na evasão dos estudantes, } \\
\text { utilizando dados de ingressantes entre 2006 e 2014. }\end{array}$ \\
\hline $\begin{array}{l}\text { O Sistema de Seleção Unificada e } \\
\text { o Preenchimento de Vagas na } \\
\begin{array}{l}\text { Universidade Federal da Grande } \\
\text { Dourados }\end{array}\end{array}$ & $\begin{array}{l}\text { Sousa (2016) } \\
\text { e pelo SiSU, no período de 2012 a 2015, na } \\
\text { Universidade Federal da Grande Dourados } \\
\text { (UFGD). }\end{array}$ \\
\hline
\end{tabular}

Fonte: Elaboração própria com base nos dados do Banco de Teses e Dissertações da CAPES.

Este grupo de trabalhos parte de perspectivas diferentes (ora com enfoque na permanência, ora com ênfase na evasão), mas que tendem a discutir a ocupação das vagas no ensino superior a partir do SiSU. Assim, baseada na escassez de investigações científicas que se dediquem à migração interna dos estudantes brasileiros, Li (2016) se propõe a compreender este movimento a partir da centralização do processo de seleção. Sousa (2015) iniciou sua investigação a partir da constatação do aumento de números de inscritos ao processo seletivo da UFPI e as sucessivas chamadas, que são necessárias para formação do corpo discente dos cursos na instituição, às vezes sem sucesso, resultando em grande número de vagas ociosas. Gómez (2015) se baseia na promessa de mobilidade geográfica que acompanha a implementação do Sistema para investigar os índices de ingresso, permanência e evasão dos cursos de Engenharia da UTFPR. De modo semelhante, Czerniaski (2014) investiga o alto índice de vagas ociosas na mesma instituição. Oliveira (2014) e Sousa (2016) partem de suas experiências adquiridas em cargos técnicos na UFGD para realização de suas pesquisas, sendo que o primeiro foca na implementação do SiSU nas universidades Federal e Estatual da Grande Dourados (UEGD e UFGD) e a segunda autora traça comparação entre vestibular e SiSU na UFGD no que tange à ocupação das vagas. Por fim, Rodrigues (2016) e Rigo (2016) desenvolvem suas pesquisas na UFV. A primeira faz análise da ocupação das vagas na universidade de acordo com as modalidades de acesso definidas pela Lei 12.711/2012, enquanto a segunda investiga, sobretudo, os cursos de licenciatura criados a partir do Programa de Apoio a Planos de Reestruturação e Expansão das Universidades Federais (REUNI).

As discussões feitas por esse segundo conjunto de dissertações se relacionam diretamente ao fato do SiSU ter rompido com a lógica da descentralização, que antecede sua implementação. Ao criar um sistema centralizado imaginava-se que a ocupação das vagas tenderia a ser mais eficiente, visto que uma maior proporção dos candidatos teria acesso via plataforma online, a todos os cursos ofertados no país inteiro pelas várias instituições públicas participantes. A expectativa era que o percentual de vagas ociosas caísse com o SiSU porque mesmo os cursos menos procurados acabariam sendo escolhidos por candidatos que percebessem, durante as simulações, que não conseguiriam entrar nos cursos mais seletivos. Esperava-se ainda uma

\begin{tabular}{l|l|l|l|l|} 
(C) Rev. Inter. Educ. Sup. & Campinas, SP & v.4 & n.1 & p.152-174
\end{tabular}
jan./abr. 2018 
ampliação significativa da mobilidade geográfica, uma vez que o sistema torna mais simples e barato se candidatar a vagas ofertadas em qualquer lugar do território nacional. As dissertações deste segundo grupo abrem o debate sobre em que medida essas expectativas eram realistas.

O terceiro grupo de dissertações analisa os possíveis efeitos democratizantes do SiSU, ou seja, avalia em que medida esse novo sistema facilitou o acesso de grupos tradicionalmente subrepresentados ao ensino superior.

Quadro 3. Trabalhos dedicados a investigação dos efeitos democratizantes do SiSU

\begin{tabular}{|c|c|c|}
\hline Título & Autoria & Objetivos \\
\hline $\begin{array}{l}\text { Acesso à Educação Superior: a } \\
\text { utilização do ENEM/SiSU na } \\
\text { Universidade Federal do Recôncavo } \\
\text { da Bahia (UFRB) }\end{array}$ & $\begin{array}{l}\text { Santos } \\
(2013)\end{array}$ & $\begin{array}{l}\text { Analisar como o modelo de seleção utilizado pela UFRB } \\
\text { através do Enem/Sisu pode se caracterizar como uma } \\
\text { política de democratização do acesso à educação superior }\end{array}$ \\
\hline $\begin{array}{l}\text { Assimetrias Socioeconômicas e } \\
\text { Acesso ao Ensino Superior - Um } \\
\text { Estudo da (Des)elitização Discente } \\
\text { na Universidade Federal do Ceará } \\
\text { (UFC) }\end{array}$ & $\begin{array}{l}\text { Abreu } \\
\left(2013^{\mathrm{a}}\right)\end{array}$ & $\begin{array}{l}\text { Identificar os efeitos que a substituição do tradicional } \\
\text { vestibular pelo ENEM/SiSU e seu ajuste à compulsória } \\
\text { política de cotas nos certames de admissão de calouros } \\
\text { exerceram sobre os níveis de elitização em âmbito } \\
\text { institucional e dos cursos superiores da UFC. }\end{array}$ \\
\hline $\begin{array}{l}\text { O Sistema de Seleção Unificada } \\
\text { (SiSU) na Universidade Federal de } \\
\text { Mato Grosso - campus Cuiabá - e a } \\
\text { relação com a democratização do } \\
\text { acesso }\end{array}$ & Luz (2013) & $\begin{array}{l}\text { Analisar o processo de implantação e desenvolvimento do } \\
\text { Sistema de Seleção Unificada (SiSU) na UFMT } \\
\text { relacionando à democratização do acesso. }\end{array}$ \\
\hline $\begin{array}{l}\text { Avaliação de Programa Social de } \\
\text { Acesso à Educação Superior: O } \\
\text { Novo Enem na Universidade } \\
\text { Federal De Lavras }\end{array}$ & $\begin{array}{l}\text { Fernandes } \\
\text { (2013) }\end{array}$ & $\begin{array}{l}\text { Analisar, sob a ótica dos atores internos, as repercussões } \\
\text { da política de democratização do acesso ao Ensino } \\
\text { Superior "novo Enem" e sua associação com o Sisu na } \\
\text { Universidade Federal de Lavras. }\end{array}$ \\
\hline $\begin{array}{l}\text { Limites e Possibilidades do ENEM } \\
\text { no Processo de Democratização do } \\
\text { Acesso à Educação Superior } \\
\text { Brasileira }\end{array}$ & $\begin{array}{c}\text { Lourenço } \\
\text { (2016) }\end{array}$ & $\begin{array}{l}\text { Verificar se o Enem, a partir de sua reformulação ocorrida } \\
\text { em 2009, tem contribuído para a democratização do acesso } \\
\text { à educação superior, e ainda, de que forma as políticas } \\
\text { implementadas pela Universidade de Brasília (UnB) têm } \\
\text { favorecido a permanência dos alunos atendidos pela } \\
\text { instituição. }\end{array}$ \\
\hline
\end{tabular}

Fonte: Elaboração própria com base nos dados do Banco de Teses e Dissertações da CAPES.

Como vemos, todos os trabalhos deste terceiro grupo são movidos pela inquietação causada pela promessa de democratização ou (des)elitização associado ao SiSU. Partindo-se de realidades institucionais diversas (UFRB, UFC, UFMT, UFLA e UnB,), estes estudiosos verificam se tal promessa se efetiva ou se funciona como mais um mecanismo de manutenção

\begin{tabular}{l|l|l|l|l|l}
\hline C Rev. Inter. Educ. Sup. & Campinas, SP & v.4 & n.1 & p.152-174 & jan./abr. 2018
\end{tabular}


do status quo, isto é, se reforçam ou contribuem para a permanência de desigualdades já evidenciadas no processo de seleção tradicional (Luz, 2013).

Cabe destacar que como a implementação do SiSU se deu concomitante ao início da vigência da Lei n. 12.711 de 2012, Lei de Cotas, é característica destas dissertações o fato delas considerarem as articulações entre o SiSU e outras políticas, especialmente a reserva de vagas. De qualquer forma, o SiSU carrega a promessa de um efeito democratizante em si mesmo, pela própria possibilidade que ele introduz de que indivíduos com perfil socioeconômico mais baixo se inscrevam em cursos de instituições distantes, aos quais eles não poderiam ter acesso pela dificuldade de se prepararem e se deslocarem para prestarem os vestibulares individualizados. Há também a possibilidade de que parte dos estudantes com um perfil social mais baixo e que tradicionalmente não se inscreviam nos cursos mais seletivos por duvidarem de sua capacidade de serem aprovados, descubram durante as simulações que ocorrem nos dias de inscrição que podem se inserir nesses cursos, decidindo assim fazer apostas mais ousadas. É preciso, então, verificar se esses efeitos democratizantes estão de fato ocorrendo e com que intensidade.

Portanto, é justificável a preocupação das dissertações deste terceiro grupo em analisar se o novo sistema de fato favoreceu a inclusão social e com que intensidade.

\section{DIFERENTES ABORDAGENS: AS METODOLOGIAS UTILIZADAS NAS DISSERTAÇÕES}

Em relação à abordagem metodológica desse corpus de 16 trabalhos, procuramos identificar como seus autores definem o terreno empírico das pesquisas e os procedimentos adotados para coleta e análise dos dados.

Quanto ao terreno empírico, pelos próprios títulos das pesquisas, é possível perceber que numerosos trabalhos $(\mathrm{n}=13)$ partem de realidades institucionais específicas para entender como tem se dado a implementação do SiSU. No interior deste grupo é possível identificar três tipos de recortes empíricos. O primeiro se refere a investigações mais amplas de instituições: Santos (2013), Sousa (2016), Fernandes (2013), Sousa (2015) e Rodrigues (2016) realizaram análises gerais sobre a UFRB, UFGD, UFLA, UFPI e UFV, respectivamente. O segundo tipo corresponde aos trabalhos que apresentam análises institucionais a partir de cursos e/ou campus específicos: Abreu (2013 $\left.{ }^{\mathrm{a}}\right)$ investigou 26 cursos da UFC, sendo estes Direito e Medicina, além de várias engenharias e licenciaturas; Rigo (2016) investigou as licenciaturas criadas a partir do REUNI na UFV (Ciências Biológicas, Física, Matemática e Química); Lourenço (2016) fez análise dos cursos de Engenharia Civil, Engenharia Elétrica, Engenharia Florestal, Engenharia Mecânica, História, Matemática, Medicina e Pedagogia da UnB; Gómez (2015) dedicou-se a investigar as engenharias da 
UTFPR - Campus Medianeira; Czerniaski (2014) analisou o Campus Francisco Beltrão da UTFPR; Luz (2013) enfatizou sua investigação no campus Cuiabá da UFMT; e, por fim, Flores (2013) tem o foco da sua pesquisa no curso de Enfermagem também da UFMT Campus Sinop. O trabalho de Oliveira (2014) representa o terceiro tipo de recorte empírico aqui identificado ao realizar análise de duas universidades sul-mato-grossense, a UFMS e UEMS.

Análises macrológicas são realizadas por Li (2016) que efetua análises estatísticas sobre as migrações intra e interestatuais; Abreu (2013) que analisa o SiSU enquanto algoritmo de matching; e Paula (2015) que investiga o perfil de todos os ingressantes do SiSU que concluíram o Ensino Médio via Enem nas edições de 2011 a 2013. Nesses três casos, as pesquisas são feitas com dados representativos do conjunto do território nacional.

Quanto às abordagens metodológicas, foram encontradas sete pesquisas cujos autores as definem como quantitativas, três definidas como qualitativas, cinco pesquisas qualiquantitativas e uma delas não define sua abordagem.

As pesquisas definidas como quantitativas foram realizadas com base em fonte de dados diversos (tais como Censo da Educação Superior, Censo Demográfico, relatórios técnicos do SiSU, ata de reuniões, demais dados do MEC, INEP e documentações das instituições a que estão relacionados, etc.). Seis (SANTOS, 2013; ABREU, 2013 ; SOUSA, 2015; PAULA, 2015; RODRIGUES, 2016; LI, 2016) realizaram análises estatísticas descritivas e inferencial e uma (ABREU, 2013) dedica-se a analisar, a luz da teoria dos jogos, o mecanismo de matching no pareamento de indivíduos no SiSU.

Cabe destacar que análises de dados em grande escala são realizadas por Li (2016) que efetua análises estatísticas sobre as migrações intra e interestatuais; Abreu (2013), que analisa o SiSU enquanto algoritmo de matching; e Paula (2015), que investiga o perfil de todos os ingressantes do SiSU que concluíram o Ensino Médio via ENEM nas edições de 2011 a 2013. Nesses três casos, as pesquisas foram feitas com dados representativos do conjunto do território nacional.

Quanto às três pesquisas que se definem como qualitativas, em ambas foram observados procedimentos mistos de coleta de dados. As duas realizam pesquisa documental atrelada a outros métodos: Czerniask (2014) produz estudo de caso por meio de aplicação de questionários e entrevistas online; Fernandes (2013) faz um estudo de caso descritivo valendo-se de entrevistas com pró-reitores, diretoras da Diretoria de Processos Seletivos e do Diretoria de Registro e Controle Acadêmico da UFLA, coordenadores de curso que existiam antes da implementação do SiSU, além de professores que eram coordenadores de curso e o pro-reitor de graduação que atuavam na época do processo de implementação e Flores (2013) investiga por meio de questionários.

\begin{tabular}{|l|l|l|l|l|l}
\hline (C) Rev. Inter. Educ. Sup. & Campinas, SP & v.4 & n.1 & p.152-174 & jan./abr. 2018
\end{tabular}


As pesquisas definidas por seus autores como quali-quantitativas também se valem de mecanismos heterogêneos de coleta de dados. Os procedimentos qualitativos de Oliveira (2014) foram a análise documental e entrevistas com agentes implementadores do $\mathrm{SiSU}^{12}$ na UFMS e UEMS, cujos dados foram analisados com base na Análise de Conteúdo. Além disso, foram feitas análises estatísticas descritivas de dados do Censo da Educação Superior. A pesquisa de Sousa (2016) valeu-se de investigação bibliográfica, pesquisa documental, entrevista com responsáveis pela implementação do SiSU na UFGD, além de dados institucionais de ingressantes de 2012 a 2015. De modo semelhante, Fernandes (2013) utilizou dados estatísticos referentes a três anos pré e três anos pós adoção do SiSU na UFLA, além de pesquisa documental, questionários e entrevistas com chefes de setores, pró-reitores, coordenadores de curso e professores da instituição. Luz (2013) fez análise de documentos e declarações oficiais (editais, atas de reuniões, sites do MEC e do SiSU) e de dados do sistema acadêmico da UFMT. Por fỉm, Lourenço (2016), além de estudar os microdados dos semestres de 2013/2 e 2014/1 referentes aos questionários socioeconômicos respondidos pelos estudantes no ato da matrícula, para alcançar o objetivo da investigação, aplicou outro questionário a estes alunos da UNB.

Por fim, há uma dissertação que não apresenta definição quanto à abordagem metodológica empregada: Gómez (2015). De qualquer forma, é possível verificar que o trabalho se utiliza de pesquisa bibliográfica documental e a análise dos dados estatísticos foi realizada, segundo a autora, a partir da categorização das informações coletadas para se evidenciar os motivos da evasão observada.

\section{DIFERENTES RESUltados: o QUE FOI PRODUZIDO PELAS DISSERTAÇõeS}

A análise das dissertações nos permitiu perceber que estas investigações dedicaram-se a observar as consequências do SiSU com base nas promessas que foram justificativas para sua implementação, sobretudo as de democratização, mobilidade estudantil e maior eficiência na ocupação de vagas, expressas no trabalho de Nogueira et al (2017). Por isso, ressalta-se que a apresentação dos resultados dos trabalhos analisados se dará nesse tópico também baseada na categorização utilizada no item 3.1: Processo de decisão, ocupação de vagas e mobilidade geográfica e democratização. Não pretendemos com esta categorização, no entanto, negar que trabalhos de um grupo não contribuam para a temática das outras categorias, pelo contrário, de modo geral, os trabalhos produzem resultados que se articulam entre si e complementamse. De qualquer forma, nosso esforço inicial será registrar as principais conclusões a que os trabalhos de cada grupo chegaram.

\footnotetext{
${ }^{12}$ Técnicos administrativos e pró-reitores.
}

\begin{tabular}{|l|c|c|c|c|c|}
\hline (C) Rev. Inter. Educ. Sup. & Campinas, SP & v.4 & n.1 & p.152-174 & jan./abr. 2018 \\
\hline
\end{tabular}


A primeira categoria, constituída pelos trabalhos de Abreu (2013), Flores (2013) e Paula (2015), demonstra como o modo de funcionamento do Sistema pode interferir no processo de tomada de decisão, contribuindo para que os estudantes façam escolhas que são mais estratégicas e que correspondem menos a suas preferências originais, pois escolhem os cursos mais acessíveis tendo em vista as notas que obtiveram no ENEM e que foram divulgadas previamente.

Abreu (2013) indica que o SiSU parece apresentar "avanços" no que diz respeito aos ganhos de eficiência do matching entre alunos e cursos em comparação com o vestibular. Outra conclusão apresentada é um contraponto ao referido avanço: que grande parte das matrículas ofertadas na primeira chamada do SiSU são rejeitadas, gerando a necessidade da realização de novas propostas de matching. Isto prolonga o tempo demandado pelo processo de seleção aumentando os custos de participação para os estudantes e, principalmente, para as instituições de ensino superior (ABREU, 2013).

O estudo de caso de Flores (2013) produziu evidências empíricas de que o SiSU tem influenciado na escolha do curso superior, causando certa "banalização" da escolha, pois o objetivo do estudante torna-se ingressar no ensino superior, independente do curso. Assim, $75 \%$ dos estudantes pesquisados (alunos do curso de Enfermagem) apontam que a nota do ENEM influenciou parcial ou totalmente na escolha pelo curso de ingresso, indicando que a escolha esteve relacionada a outros fatores que não ao desejo genuíno dos estudantes. Assim, metade dos pesquisados não ingressou no curso desejado (Medicina) e pretende realizar outro processo seletivo.

Paula (2015), ao investigar os estudantes que obtiveram a certificação do Ensino Médio pelo ENEM e ingressaram no Ensino Superior por meio do SiSU, percebe que as escolhas estão diretamente relacionadas ao nível socioeconômico e as pontuações do estudantes. Assim, mesmo no interior de grupos com certa homogeneidade (em sua maioria, os investigados são egressos de escolas públicas com renda entre dois e cinco salários mínimos), verificou-se que quanto maior a vulnerabilidade, menor a nota e maior a chance da escolha ser por cursos socialmente desprestigiados. O que demonstra que mesmo em situações em que o sistema se cria novas oportunidades, elas são aproveitadas conforme o perfil escolar e nível socioeconômico dos candidatos.

As observações feitas nos trabalhos acima de que parte significativa dos candidatos não estaria escolhendo os cursos que mais desejam apontam para uma possível relação entre a forma de escolha dos cursos no SiSU e o aumento recentemente identificado nos índices evasão. As discussões a esse respeito são aprofundadas na segunda categoria de trabalhos aqui destacada: aqueles cuja temática é mobilidade geográfica estudantil e a ocupação das vagas. 
No estudo de caso realizado por Rigo (2016) na UFV, os estudantes entrevistados assinalam motivos para sua evasão. Dentre eles, consta desestímulo, inadequação ao curso, problemas pessoais, a excessiva exigência do professor (sobretudo em se tratando dos cursos de ciência exatas), distância de casa, distanciamento entre professor e aluno, dificuldade com os conteúdos das disciplinas. Um fator interessante nestes casos foi a tendência de parte dos alunos de "ressignificar a evasão", utilizando-a como estratégia para alcançar outros cursos, reorientando a escolha inicial, ou para entrar novamente no mesmo e refazer algumas disciplinas nas quais os estudantes haviam obtido baixo desempenho, melhorando sua média de rendimento na universidade. Assim, segundo a autora, nesses casos a evasão está relacionada às aspirações mais elevadas dos estudantes, representando uma estratégia para alcançar o sucesso escolar dentro do próprio curso ou dentro de outro curso almejado.

Problemas relacionados na ocupação das vagas foram abordados em diversos trabalhos. Li (2016) verificou que a adesão ao SiSU eleva a probabilidade de evasão no primeiro ano em 4,5 pontos percentuais, bem como aumenta a chance de evasão antes de o aluno concluir o curso. Sousa (2015) aponta que um dos principais gargalos do SiSU é o não preenchimento das vagas. $\mathrm{Na}$ instituição investigada (UFPI), o pesquisador notou que $73,8 \%$ dos candidatos convocados em primeira chamada não efetivam sua matrícula, sobretudo no campus localizado no interior do estado do Piauí. Os motivos para sobra de vagas ele encontra, como discutido inicialmente, no comportamento estratégico do alunado. Assim,

\begin{abstract}
a não efetivação da matrícula pelos convocados no SiSU/UFPI e com isso a sobra de vagas é, portanto, um fenômeno ocasionado pelas regras e condições objetivas do sistema, que ajustam os fatores de ordem macrossociológica e individuais dos estudantes durante a fase de inscrição, contribuindo para que a escolha do curso e do campus seja apenas parte da estratégia de se obter êxito no jogo (SOUSA, 2015, p. 12).
\end{abstract}

De modo semelhante, Sousa (2016) aponta que os dados analisados em sua investigação mostraram que após a adesão da UFGD ao SiSU, em 2014, houve redução da taxa de ocupação de vagas, destacando que se comparado ao tradicional vestibular, a ocupação era mais eficaz. Na instituição investigada, há um procedimento que tem sido profícuo, segundo a autora, para filtrar os estudantes habilitados: a chamada demonstração de interesse online que inicialmente foi implementada no curso de Medicina. Trata-se de um procedimento em que o estudante manifesta interesse online a partir da primeira chamada, após a disponibilização da Lista de Espera do SISU e antes da convocação para a efetivação da matrícula. Assim, selecionam-se mais eficazmente aqueles que têm intenção de ocupar as vagas, aligeirando, evitando muitas chamadas da lista de espera.

Para Oliveira (2014), o objetivo de melhorar o processo de ocupação das vagas não está sendo alcançado na UFMS e na UEMS, os percentuais de evasão anual, de desistentes ou desligados, de vagas remanescentes, entre outros indicadores que já eram ruins na instituição, 
foram ampliados. $\mathrm{O}$ autor pondera que o fato de mais alunos terem acesso ao exame e de o SiSU incentivar a migração dos estudantes, por si só, não garante uma otimização da ocupação das vagas.

Rodrigues (2016) associa a ineficiência na ocupação das vagas não somente ao SiSU, mas também à Lei de Cotas, demonstrando que a evasão aumentou consideravelmente após o início da reserva de vagas. Além disso, sugere que este aumento pode estar associado à amplicação de oportunidades, advinda de outros programas que têm como objetivo a promoção do acesso ao ensino superior (ProUni e Fies). Li (2016), em contraponto, mostra que alunos negros apresentam probabilidades menores de evasão no primeiro ano, assim como alunos que recebem apoio social (que são aqueles beneficiados pela Lei de Cotas).

O estudo de caso de Czerniask (2014) evidencia como a promessa de mobilidade geográfica pode causar efeito inverso à democratização nas instituições do interior. Constatou-se por meio dos dados coletados

[...] que, para a UTFPR, campus Francisco Beltrão, no que tange ao preenchimento das vagas dos cursos de graduação, o SiSU não foi assertivo. Haja vista que as notas de corte dos alunos egressos do ensino médio da região não estão à altura da nota de corte dos alunos oriundos dos grandes centros e de muitas outras regiões do país, cita-se, por exemplo, o Sudeste brasileiro. Desta forma, os alunos classificados, por serem de regiões distantes da nossa, os quais sequer imaginam onde fica o Sudoeste do Paraná, em sua maioria, optam por cursar uma universidade menos distante geográfica e culturalmente de sua residência de origem, sem saber, por óbvio, que tal escolha impede que um aluno já morador na região, possa usufruir desta vaga (CZERNIASK, 2014, p. 98).

De modo geral, estes trabalhos destacam a importância de políticas de permanência que assegurem aos estudantes condições de manutenção em instituições distantes da sua localidade de origem. Assim, esses resultados têm uma importante implicação política: sugerem que oferecer apoio social ao aluno ingressante pode ser uma solução para a redução da evasão, garantindo não somente uma democratização do acesso, mas a permanência em qualquer instituição no território nacional.

Assim, chegamos aos cinco trabalhos do terceiro agrupamento, aqueles cuja temática recai sobre os supostos efeitos democratizantes do novo Sistema. Neste grupo de dissertações percebeu-se que as análises estão muito ligadas aos efeitos da Lei de Cotas e outras políticas que visam à democratização da Educação Superior.

Este é o caso de Abreu (2013), que discutiu a “(des)elitização" na UFC a partir da implementação do Sistema. O autor notou que a adesão ao ENEM/SiSU não ocasionou mudança considerável no nível de elitização. Em momento posterior, o advento das cotas propiciou uma leve (des)elitização. No entanto, sugere que esse processo ocorreria de forma 
mais acentuada se o quesito renda familiar, em vez do tipo de escola de ensino médio, fosse usado como critério principal na seleção dos cotistas. No que se refere ao primeiro grupo de cursos por ele investigado, os chamados imperiais (Direito, Medicina e Engenharia), verificou- se que tanto o ENEM/SiSU quanto o sistema de cotas contribuíram para deselitizacão. Já com relação aos cursos de licenciatura, observou- se que o ENEM/SiSU funcionou de forma contrária à esperada, induzindo a uma elitização.

Luz (2013) reforça as mesmas conclusões evidenciando que "o SiSU na UFMT caminha na contramão de uma política efetiva de democratização do acesso” (p. 166). Para a autora, a proposta do acesso por meio de uma avaliação única é uma premissa contraditória, visto que nem mesmo são consideradas as características peculiares do sistema de ensino básico brasileiro para a elaboração da avaliação. A unificação da seleção seria incoerente num país onde qualitativamente o ensino médio encontra-se muito diferenciado.

Ademais,

O discurso de uma possível democratização do acesso disseminada para a defesa do ENEM e SiSU, apresentando-os como uma política que inibiria a desigualdade do acesso, não consegue alcançar os objetivos de uma democratização. Seus critérios continuam os mesmos, e a lógica da 'igualdade de oportunidade' continua a mesma construída historicamente no ingresso ao ensino superior brasileiro (LUZ, 2013, p. 168).

Quanto a isso, Santos (2013) observa que as características do processo seletivo para o Ensino Superior continuam fortemente meritocráticas e com grande seletividade em cursos de maior prestígio social. No entanto, a adoção do SiSU na UFRB promoveu a democratização da possibilidade de concorrência na medida em que permitiu que um maior número de pessoas tivesse oportunidade de participar no processo, favorecendo, sobremaneira, um perfil de candidatos cuja origem geográfica, residentes do interior da Bahia, fora da capital, foi alcançada pela UFRB.

Percebe-se que os trabalhos analisados têm em comum o apontamento de que o Novo ENEM/ SiSU oferece a mesma condição para realização das provas e incentiva a mobilidade por meio do incentivo à concorrência sem necessidade de deslocamento, entretanto os que ingressam nos melhores cursos continuam sendo aqueles com melhor capital cultural e econômico. Os demais, via-de-regra, ficam pelo caminho, ou se contentam com cursos menos prestigiados e mais próximos de seu local geográfico de origem. Assim,

o que se percebe é que "o discurso de concessão das mesmas oportunidades de acesso, desconsiderando as assimétricas condições regionais, sociais e econômicas, torna a propagada mobilidade acadêmica um discurso excludente, fortalecendo a desigualdade educacional” (LOURENÇO, 2016, p.118).

Outra conclusão a ser destacada é a de Fernandes (2013). A autora destaca que o "novo Enem" está, na verdade, funcionando como uma medida paliativa, tendo em vista que o 
governo federal atua apenas no meio da cadeia educacional, facilitando o ingresso no ensino superior, mas deixa de investir na mesma proporção no ensino básico. O ideal, no entanto, seria o governo investir na qualidade do ensino fundamental e médio para que os alunos tenham um melhor aproveitamento e consequentemente mais oportunidades de acesso às instituições.

Apesar das críticas, todos os trabalhos aqui apresentados destacam que o SiSU é um fenômeno ainda recente, e visto que a cada ano há novas modificações nas suas normas e formas de execução, ponderam que as análises precisam ser continuadas e devem investigar se realmente o sistema está funcionando como facilitador de um acesso mais democrático.

\section{CONSIDERAÇÕES FINAIS}

Desde sua implantação, o SiSU vem apresentando uma crescente adesão, tanto dos estudantes, que buscam acesso ao ensino superior, quanto das instituições públicas, as quais passam a utilizá-lo no lugar do vestibular tradicional. Diante disso, faz-se essencial verificar como ele tem interferido na dinâmica de acesso ao Ensino Superior: tornando a alocação das vagas mais ou menos eficiente e contribuindo ou não para os processos de expansão e democratização deste nível de Ensino.

Neste trabalho, analisamos como o SiSU foi investigado nas pesquisas sobre o tema encontradas no Banco de Teses e Dissertações da CAPES. Acreditamos que a realização de trabalhos como este possibilita contribuir para o amadurecimento da produção científica sobre o SiSU, ao evidenciar quais são os temas mais abordados, as perspectivas metodológicas mais utilizadas e as áreas que precisam ser mais exploradas.

Em relação a este último aspecto, é conveniente ressaltar que as análises desenvolvidas nas dissertações aqui consideradas não se esgotam em si mesmas. Ao contrário, abrem caminho para a elaboração de uma ampla gama de outras investigações, tendo em vista o pouco tempo de criação do Sistema e o grande leque de dúvidas ainda existentes sobre os efeitos do SiSU. Entre outros aspectos, acreditamos que essas investigações deverão tratar do modo como o novo sistema afeta a escolha dos cursos superiores e, assim, a distribuição de alunos de diferentes perfis sociais e escolares entre os mesmos, com consequências mais ou menos democratizantes. Outro tema central certamente será a evasão, que parece ter se ampliado significativamente. Finalmente, novas pesquisas devem surgir sobre as políticas públicas de assistência estudantil, que se tornaram essenciais, especialmente para a permanência dos alunos migrantes. 


\section{REFERÊNCIAS}

ABREU, Luís. Mecanismos de Seleção de Gale-Shapley Dinâmicos em Universidades

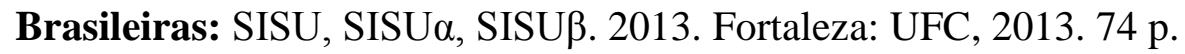

ABREU, Raimundo Luigi Santos de. Assimetrias socioeconômicas e acesso ao ensino superior - um estudo da (des)elitização discente da Universidade Federal do Ceará (UFC). 2013. Fortaleza: UFC, 2013. 151 p.

ABREU, Luís; CARVALHO, José R. Análise do jogo induzido pelo mecanismo SiSU de alocação de estudantes em universidades. In: ENCONTRO NACIONAL DE ECONOMIA ANPEC, 42., Natal, 2014. Anais... Natal: [s.n.] 2014.

ALMEIDA, Aléssio Tony Cavalcante de; SIQUEIRA, Liédje Bettizaide Oliveira de; SILVA, Andrea Ferreira da; SOBRAL, Eryka Fernanda Miranda; ROCHA, Evandro Farias.

Estratégia Safe Choice sob menor Incerteza e Alocação Ineficiente no Ensino Superior Brasileiro. In: ENCONTRO REGIONAL DE ECONOMIA, 21., 2016, Fortaleza. Anais... Fortaleza: [s.n.], 2016.

BRASIL. Ministério da Educação. Proposta à Associação Nacional dos Dirigentes das Instituições Federais de Ensino Superior. 2009.

BRASIL.. Ministério da Educação. Termo de Referência. Novo ENEM e Sistema de Seleção Unificada. NET, 08 abr. 2009b. Disponível em:

<https://www.ufpe.br/ufpenova/images/documentos/termo.pdf>. Acesso em: 22 set. 2017.

BRASIL.. Ministério da Educação. Portaria MEC n. 2, de 26 de janeiro de 2010. Institui e regulamenta o Sistema se Seleção Unificado. NET, 26 jan. 2010. Disponível em: < http://ces.ufpel.edu.br/vestibular/download/2009i/portaria_sisu_diario.pdf > . Acesso em: 02 mai. 2017.

BRASIL. Presidência da República. Lei No 12.711. Brasília: 29 de agosto de 2012.

BRASIL. Edital nº 5, de 13 de janeiro. Sistema de Seleção Unificada - SiSU. 2017. COSTA, Clayton Pereira. Noções básicas de estatística através de um tema integrador. 2013. Maceió: UFAL, 2013. 84 p.

CZERNIASKI, Lizandra Felippi. Políticas públicas de democratização do ensino superior: um estudo sobre a ocupação das vagas nos cursos de graduação na Universidade Tecnológica Federal do Paraná - Campus Francisco Beltrão. Maringá: UEM, 2014. 111 p.

DUBET, François. Qual democratização do ensino superior?.Cad. CRH, Salvador, v. 28, n. 74, p. 255-266, Aug. 2015.

FERNANDES, Aline Marques. Avaliação de Programa Social de Acesso à Educação Superior: o novo ENEM na Universidade Federal de Lavras. Lavras: UFLA, 2013. 101 p. 
FLORES, Cézar Augusto da Silva. A escolha do curso superior no sistema de seleção unificada - SiSU: o caso do curso de enfermagem da Universidade Federal de Mato Grosso, Campus Universitário de Sinop. Cuiabá: UFMT, 2013. 181p.

FRITSCH, Rosângela et al. A evasão nos cursos de graduação em uma instituição de ensino superior privada. Revista Educação em questão, Natal, v.52, n 38, p.81-108, maio/ago.2015.

GAIA, Elizabeth Silva. Elaboração do manual de orientações do processo seletivo para ingresso inicial nos cursos de graduação da Universidade Federal do Triângulo Mineiro pelo Sistema de Seleção Unificada (SiSU). Uberada: UFTM, 2017. 118 p.

GÓMEZ, Magela Reny Fonticiella. Acesso e permanência de alunos de engenharia da UTFPR - Câmpus Medianeira. Marília: UNESP, 2015. 123 p.

LI, Denise Leyi. O Novo ENEM e a plataforma SiSU: efeitos sobre a migração e a evasão estudantil. São Paulo: USP, 2016. 108 p.

LOURENÇO, Vânia Maria. Limites e Possibilidades do ENEM no Processo de Democratização do Acesso à Educação Superior Brasileira. Brasília: UNB, 2016. 145 p.

LUZ, Jackeline Lourenço Noronha da. O Sistema de Seleção Unificada (SiSU) na Universidade Federal de Mato Grosso - campus Cuiabá - e a relação com a democratização do acesso. Cuiabá: UFMT, 2013. 186 p.

MERLE, Pierre. La démocratisation de I’enseignement. Paris: La découverte, 2009.

NOGUEIRA, Cláudio Marques Martins; NONATO, Bréscia; RIBEIRO, Gustavo Meirelles; FLONTINO, Sandra Dantas. Promessas e Limites: o SiSU e sua implementação na Universidade Federal de Minas Gerais. Belo Horizonte: Educação em Revista [online]. 2017, vol. 33. Disponível em: <http://www.scielo.br/pdf/edur/v33/1982-6621-edur-33e161036.pdf >. Acesso em: 20 de out. de 2017.

OLIVEIRA, Jonas de Paula. Acesso a Educação Superior pelo ENEM/SiSU: uma análise da implementação nas universidades sul-mato-grossenses. Dourados: UFGD, 2014. 134 p.

PAULA, Teófilo Francisco de. Análise das escolhas do curso superior pelos certificandos partici-pantes do ENEM, que ingressaram em uma IES, por meio do SISU, no período 2012-2014. Florianópolis: UFSC, 2015. 136 p.

RIGO, Júlia da Silva. Percursos de Formação de Estudantes de Licenciatura Noturna na UFV: ENEM, SiSU e Evasão. Viçosa: UFV, 2016. 136 p.

RODRIGUES, Aline Xisto. Políticas Públicas de Acesso ao Ensino Superior: os Resultados do SiSU na Universidade Federal De Viçosa. Florestal: UFV, 2016. 61 p. 
ROMANOWSKI, Joana Paulin; ENS, Romilda Teodora. As pesquisas denominadas do tipo 'Estadoda-arte' em educação. Paraná: Diálogo educacional, 2006. p. 37-50.

SANTOS, Janete dos. Acesso à educação superior: a utilização do ENEM/SISU na Universidade Federal do Recôncavo da Bahia. Salvador: UFBA, 2013. 126 p.

SANTIN, Andria Caroline Angelo. O desenvolvimento local e a relação com as políticas públicas REUNI e SISU: o estudo de caso da Universidade Federal de Pelotas. Pelotas: UFPel, 2014. $236 \mathrm{f}$.

SOUSA, Marcela Regina Porta de. O Sistema de Seleção Unificada e o Preenchimento de Vagas na Universidade Federal da Grande Dourados. Dourados: UFGD, 2016. 97 p.

SOUSA, Marcio Soares de. Os efeitos do SiSU no acesso ao ensino superior: os fatores condicionantes da não ocupação das vagas pelos convocados na Universidade Federal do Piauí. Teresina: UFPI, 2015. 110 p.

\section{${ }^{1}$ Sobre os autores}

\section{Thainara Cristina de Castro Ariovaldo}

E-mail: thainaracastro_@hotmail.com / ORCID: http://orcid.org/0000-0003-1997-2611

Universidade Federal de Minas Gerais - Brasil

Mestranda em Educação pela Fac. de Educação / Universidade Federal de Minas Gerais [UFMG]. Cláudio Marques Martins Nogueira

E-mail: cmmn@uol.com.br / ORCID: http://orcid.org/0000-0001-7913-5669

Universidade Federal de Minas Gerais - Brasil

Doutor em Educação pela Fac. de Educação / Universidade Federal de Minas Gerais [UFMG]. 